\section{The case for neutrality on assisted dying a personal view}

Dr Gerada's article provoked an almost unprecedented mailbag at the BJGP, and many other responses have been posted on our discussion forum.

Roger Jones,

Editor

\section{Editor's choice}

I thought that the article Clare Gerada wrote for the BJGP was beautifully written and perfectly expressed.'

My mother (Ann McPherson) was a GP who felt strongly through her career that she could not do enough for patients who had a terrible time while they were dying. Unfortunately her death from pancreatic cancer, despite optimal palliative care, was prolonged and unpleasant. It is a difficult issue and one that provokes strong emotions but overall this should now be a question about individual choice. I was so pleased to read such a balanced view about the need for neutrality.

Tess McPherson,

Consultant Dermatologist, Churchill

Hospital, Oxford.

E-mail: tess.mcphersonamsd.ox.ac.uk

\section{REFERENCE}

. Gerada C. Viewpoint: The case for neutrality on assisted dying - a personal view. Br J Gen Pract 2012; 62(605): 650 .

DOI: 10.3399/bjgp13X661048

Dr Gerada is to be congratulated for her proposal that the Royal College of General Practitioners should adopt a position of neutrality over the issue of assisted dying. ${ }^{1}$ As she points out, Parliament should decide on whether the law should be changed, and the role of the College should be a resource of expert opinion on issues such as prognosis, safeguards, and the practicalities of helping terminally ill patients who wish to die.

By being neutral the College can foster reasonable rational debates, allowing the voices of all to be heard with equal respect, and will set an example for other Colleges to follow.

\section{Sarah Wookey,}

West Bar Surgery, South Bar House, 6 Oxford Road, Banbury, OX16 9AD.

E-mail: sarah.wookeylanhs.net

\section{REFERENCE}

1. Gerada C. Viewpoint: The case for neutrality on assisted dying - a personal view. Br J Gen Pract 2012; 62(605): 650 .

DOI: 10.3399/bjgp13X662885

I have read Dr Gerada's article in which she recommends that decisions on end of life be made by Parliament and suggests that doctors ought not to have an input in such matters. ${ }^{1}$

However, within the article Lord Falconer's report is quoted as if it were a fair assessment of the 'assisted dying' debate, when the membership of his committee was composed almost completely of supporters of euthanasia. The fact that Lord Falconer intends to reintroduce a further debate in 2013 suggests that he represents a pressure group and cannot by any stretch of the imagination be assumed to be a neutral observer.

Also quoted with approval was the introduction of the 'Abortion Act' when Lord Steele fronted the campaign but innocently had not perceived the floodgate he was helping to open. As a consequence, despite the protestations at its introduction that a conscience clause would protect nurses and doctors who had moral objections to being involved, there now exists a speciality area of medicine from which individuals are being excluded.

Doctors have every right to be involved. They will be the ones who will be asked to supply the drugs or to insert the venflon or needle. When opposing euthanasia, we are asking not to be given an increased power to kill, but to be given protection from pressures from individuals, relatives, administrators, and the State, who may desire the ending of lives prematurely.
Quoting bad cases as done in this article, is not conducive to producing good law.

Dr Gerada retires with well-earned credit from a time of challenge and difficult leadership. I deeply regret that she should as a final act, use her position to sway opinion in our College in a particular direction.

Eric J Mackay,

4 Conifer Place, Lenzie, Glasgow, G66 4EJ. E-mail: mack305latiscali.co.uk

\section{REFERENCE}

1. Gerada C. Viewpoint: The case for neutrality on assisted dying - a personal view. Br J Gen Pract 2012; 62(605): 650 .

DOI: 10.3399/bjgp13X662894

Clare Gerada has done a lot of good things since becoming Chair of Council at the RCGP: her regular e-mail updates are very good. Unfortunately her ill-judged article on assisted dying and changing the College position on the issue is unhelpful and deeply flawed.

She makes the common mistake of giving weight to the Falconer commission. It is well recognised that the Falconer commission was a propaganda vehicle for Dignity in Dying, the pro-euthansia pressure group. The commission was chaired by Lord Falconer, a member of Dignity in Dying and a prominent advocate of euthanasia and assisted suicide, the commission was by Dignity in Dying, it was funded by Terry Pratchett, a celebrity member of Dignity in Dying, and 12 out of 13 of the commission members were known supporters of assisted suicide and euthanasia. So the Falconer commission was in no way an unbiased and neutral observer on the issue, but a strongly pro-euthanasia and pro-assisted suicide report. Clare Gerada is either being naive or economical with the truth if she believes that the Falconer commission provides an unbiased and fair opinion.

Although advocating neutrality on the issue sounds very reasonable, it does in fact shift the College position towards legalising assisted suicide and euthanasia, so it is not a 'neutral' position to advocate this change. Repeated polls have shown the majority of 